\title{
Where did mountain pine beetle populations in Jasper Park come from? Tracking beetles with genetics
}

\author{
by Stephen A.L. Trevoy ${ }^{1 *}$, Jasmine K. Janes ${ }^{2,3^{*}}$, and Felix A.H. Sperling ${ }^{1}$
}

\begin{abstract}
The invasion of mountain pine beetle (Dendroctonus ponderosae Hopk.) into Alberta has been an ongoing concern for forest management. The beetle's recent appearance and spread in Jasper National Park now poses ecological and economic threats to forestry in regions to the east. By applying recent advances in genetic typing and analysis, we show that the beetle population in Jasper is comprised of mixed individuals combining genetic signatures of both northern and southern beetles. Coupled with current monitoring methods, genetic markers can be used to identify the origin of novel populations, facilitate precise monitoring of beetle expansion and potentially inform targeted management strategies.
\end{abstract}

Keywords: Dendroctonus ponderosae, population genomics, Jasper, Yellowhead County, pest management, park management

\section{RÉSUMÉ}

L'invasion de dendroctone du pin ponderosa (Dendroctonus ponderosae Hopk.) en Alberta na cessé de préoccuper les aménagistes forestiers. Lapparition récente du dendroctone et sa dispersion dans le Parc national de Jasper constituent maintenant une menace écologique et économique pour les forêts dans les régions plus à l'Est. En misant sur les derniers développements en matière de caractérisation et d’analyse génétique, nous avons pu montrer que les populations de dendroctone à Jasper sont constituées d'un ensemble d'individus combinant les signatures génétiques à la fois de dendroctones du nord et du sud. Jumelés aux méthodes actuelles de surveillances, les marqueurs génétiques pourraient aider à identifier la provenance de nouvelles populations, faciliter le suivi détaillé de lexpansion du dendroctone et potentiellement aider à élaborer des stratégies d’aménagement ciblées.

Mots-cles : Dendroctonus ponderosae, génomique des populations, Jasper, Yellowhead County, gestion des ravageurs, aménagement des parcs

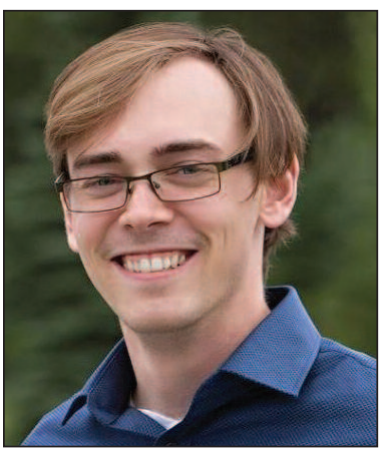

Stephen A.L. Trevoy

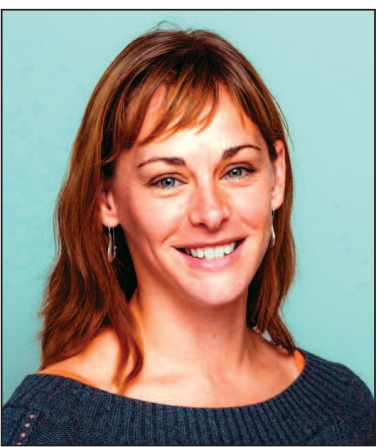

Jasmine K. Janes

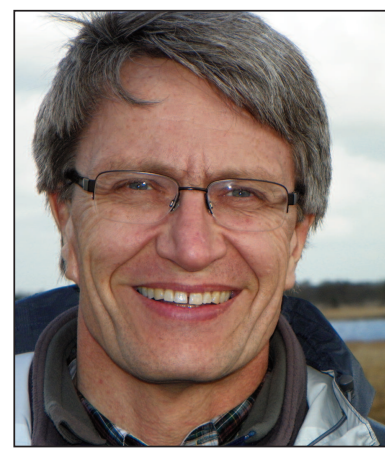

Felix A.H. Sperling southeast. Damage to these forests would cause significant social, economic and ecological losses, as well as providing more MPB habitat that could exacerbate the current epidemic. Currently, the source of the Jasper infestation has been debated. The infestation may represent a slow spread of beetles from the north, around the Grande Prairie area (Hopkins-Hill 2017), which had extremely high numbers of beetles in 2009 (Bleiker et al. 2011, Pellow et al. 2011). This northern population is believed to have spread southeast, resulting in an indigenous population near the town of Hinton by 2015 (Jasper National Park 2016). Alternatively, the Jasper infestation could have arrived through affected forests from the west around Mt. Robson Provincial Park, which has been in active outbreak since at least 2015 (Jasper National Park 2016). Recent

\footnotetext{
${ }^{1}$ Department of Biological Sciences, University of Alberta, Canada; corresponding author: strevoy@ualberta.ca

${ }^{2}$ School of Environmental and Rural Sciences, University of New England, Australia; corresponding author: jjanes@une.edu.au

${ }^{3}$ Biology Department, Vancouver Island University, Canada

${ }^{*}$ Co-first authors
} 


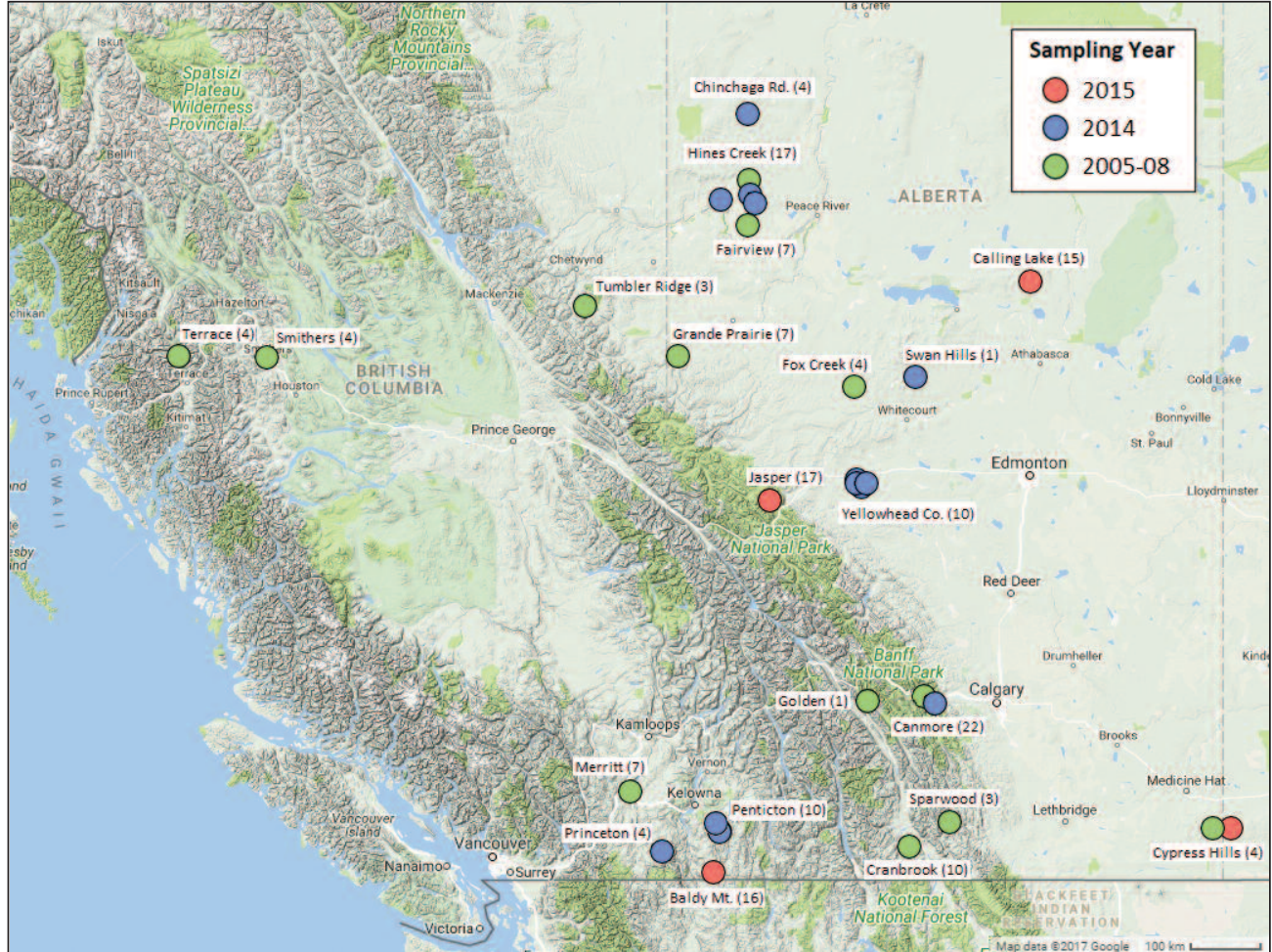

Fig 1. Map of mountain pine beetle collection sites organized by collection year. A total of 175 MPB were collected from 33 sites at 25 localities. Number of specimens sampled is in parentheses. Three U.S. localities are not shown (one specimen of each from Wyoming, Nevada and Washington).

research on MPB population genetic structure can contribute to identifying and understanding such movements of MPB on the landscape.

MPB numbers have been rising in Canada since the early 1990s, devastating 16.3 million hectares of forest within British Columbia and western USA by 2011 (Bentz et al. 2010, de la Giroday et al. 2011). Expansion into northern Alberta in 2006 (Robertson et al. 2009, Safranyik et al. 2010) has positioned the beetle to colonize a new host species, jack pine (Pinus banksiana Lamb.) (Cullingham et al. 2011), which is a major component of the boreal forest across North America. Expanded research on the MPB system has targeted better prediction, management, and prevention of outbreaks, including studies on their ecological impacts (Carroll et al. 2003, Raffa et al. 2008), fungal associations (Roe et al. 2010, Tsui et al. 2010, DiGuistini et al. 2011), host suitability and distribution (Cullingham et al. 2011, Erbilgin et al. 2014, Rosenberger et al. 2017a), beetle population dynamics (Hicke et al. 2006, Lachowsky and Reid 2014, James et al. 2016, Cooke and Carroll 2017, Rosenberger et al. 2017b), and population genetic and genomic structure (Samarasekara et al. 2012, Keeling et al. 2013, Janes et al. 2014, Janes et al. 2016, Batista et al. 2016, Janes and Batista 2016).

Here we draw on recent literature and new research to address questions and concerns raised over the 'Jasper beetles'. Using genome-wide sampling of DNA markers, we provide context for the likely source populations of MPB in the Jasper region.

\section{Materials and Methods}

A total of 175 MPB were collected from 33 sites throughout British Columbia and Alberta between 2007 and 2015 (Fig. 1, Online Supplementary Appendix 1). Beetles were either stored in $95 \%$ ethanol at $-20{ }^{\circ} \mathrm{C}$ or stored dry at $-80{ }^{\circ} \mathrm{C}$. In addition, wild-caught MPB from the Smokey River Lowlands (SRL) south of Grande Prairie ( $54^{0} 21.376^{\prime}$; N $118^{\circ} 19.112^{\prime}$ W) and the Burnco Quarry (BQ) near Canmore $\left(51^{\circ} 04.026^{\prime} \mathrm{N}\right.$; $115^{\circ} 17.237^{\prime} \mathrm{W}$ ) were used as breeding pairs to produce artificially hybridized individuals of northern SRL and southern BQ descent. These sites were chosen to represent the two large-scale beetle populations in Alberta known from prior research (Samarasekara et al. 2012, Janes et al. 2014). Thirteen offspring from seven of these SRL x BQ crosses (1-3 offspring per pair) were added to the 175 samples, giving a total of 188 samples.

Genomic DNA was extracted using QIAGEN (Toronto, ON, Canada) DNEasy Blood \& Tissue kits according to manufacturer's instructions. DNA was quality checked using Qubit flourometric assay (Waltham, MA, USA) and standardized to $20 \mathrm{ng} / \mu \mathrm{l}$. Samples were genotyped using a doubledigest (PstI-MspI), 96-plex genotyping-by-sequencing (GBS) protocol (Elshire et al. 2011, Poland et al. 2012) at l'Institut de Biologie Intégrative et des Systems (IBIS) of Laval University and the Molecular Biology Services Unit (MBSU) of University of Alberta. A total of 63 samples were sequenced with an Illumina NextSeq 500 for 75 bp single-end reads, and 125 samples were sequenced using an Illumina HiSeq 2000 for 
100 bp single-end reads. Campbell et al. (2017) contains further details on library preparation, and supports the consistency and reproducibility of GBS across both preparations and platforms.

Reads (short sequences of DNA) were quality checked using FastQC v0.11.05 (Andrews 2010) and demultiplexed in the STACKS v1.41 pipeline (Catchen et al. 2013). Barcodes and adapters were removed with Cutadapt v1.10 (Martin 2011) to produce a uniform read length of 62 bp for alignment in STACKS (Catchen et al. 2013). After removing reads with poor sequence quality and low alignment to the reference genome, 1.1 billion reads remained. GBS data were mapped to the MPB draft reference genome (Keeling et al. 2013) using BWA-MEM v0.7.12 (Li and Durbin 2009) with option $-\mathrm{c}=1$ to remove reads that did not uniquely map to the reference. Each sample retained an average of $85.0 \%$ of its unique reads. Variants (variable genetic markers in the form of single nucleotide polymorphisms, SNPs) were detected in the STACKS refgen pipeline using default parameters, except for: minor allele frequency $=5 \%$, minimum quality score $=$ 20 , and minimum read depth $=7$.

VCFtools v0.1.12b (Danecek et al. 2011) was used to identify and remove loci containing missing data. A total of 984 variants were identified from these mapped reads, forming the basis for further analysis. An individual-by-individual genetic distance matrix (uncorrected "p") was calculated using PAUP v4.0a152 (Swofford 2002). These genetic distances, which relate to genetic similarity, were visualized using principal coordinates analysis (PCoA) with the ade 4 package (Dray et al. 2007) in R (R Core Development Team 2009). PCoA is commonly used to explore and visualize the similarity or dissimilarity among samples, displaying the axes that explain the largest portion of the variation present in the data. For each of the resulting sampling clusters, ellipses based on $95 \%$ confidence intervals from the centroid of the cluster were overlaid using ggplot2 (Wickham 2009). These ellipses provide an additional means of assessing confidence in fit to each cluster.

\section{Results and Discussion}

Fig. 2 shows a clear separation of northern (blue and green) and southern (red) populations along axis 1 (45.7\% of total variance), in agreement with prior studies using other genetic markers (Samarasekera et al. 2012, Janes et al. 2014). The northern cluster represents populations from the Peace River region (including Grande Prairie) to north-central Alberta, with samples from the northwest (Terrace, Smithers, and Tumbler Ridge in BC) separated further (Fig. 2). This suggests a degree of separation by distance over the vast range of the northern MPB population. Beetles from Jasper (purple) and the SRL $x$ BQ (orange) crosses were intermediate to northern and southern populations. Variability among SRL $x$ BQ samples is greater than that of wild-caught Jasper MPB, as shown by its smaller ellipse, nested within SRL x BQ's ellipse (Fig. 2). Jasper beetles, therefore, fall within the expected variation found within artificially hybridized north/south crosses of MPB. The higher degree of variation within SRL $x$ BQ may be explained by pre-emergence mating among siblings within a bolt, a known occurrence in MPB (Bleiker et al. 2013, Janes et al. 2016).

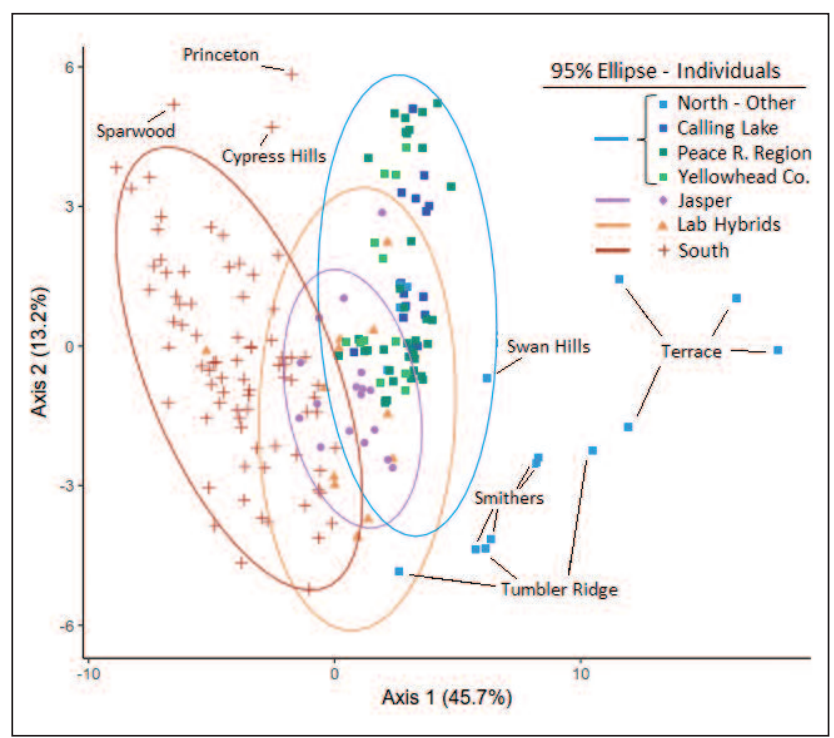

Fig 2. Principal coordinate analysis of 175 wild-caught mountain pine beetles, plus 13 lab-bred specimens added to simulate intermediates between northern and southern populations. Ellipses give 95\% confidence intervals for populations, with the overall northern population sub-divided by colour for areas of particular management interest.

MPB from Yellowhead County, east of Jasper Park, were most similar to the northern cluster (Fig. 2), suggesting a northern source for Yellowhead beetles in 2014, a year before MPB numbers were recognized as an outbreak in Jasper. Thus, our data supports the earlier movement of beetles from the Grande Prairie area into Yellowhead County, largely confirming a northern origin for this area. In contrast, the intermediate position of the wild-collected MPB from Jasper suggests either an existing admixed population from BC expanding eastward or converging invasive fronts meeting secondarily in Jasper. The presence of previously identified intermediate populations around Valemount (Janes et al. 2014), in addition to increasing numbers of beetles west of Jasper appears to support a central BC origin for the Jasper area. While this study has considerably fewer individuals than previous studies of MPB (i.e., Samarasekera et al. 2012, Janes et al. 2014, Batista et al. 2016), we find very similar patterns of genetic diversity and structure suggesting that larger numbers of variants can increase precision and power for low sample numbers. This effect could reduce the need for intensive sampling in future genetic studies. However, to determine the trajectory and genetic composition of the most recent outbreaks additional sampling in leading-edge populations will be necessary.

Regardless of its exact source, the intermediate nature of the MPB population in Jasper provides unique challenges and advantages. For example, hybrid populations, even within the same species, are recognized as important evolutionary components in both plants and animals because they can rapidly generate novel genetic material for adaptation (Rieseberg and Burke 2001, Mallet 2007, Janes and Hamilton 2017). Janes et al. (2014) and Batista et al. (2016) have consistently identified 
strong selection differences on known metabolic genes between northern and southern populations. Thus, the intermediate nature of beetles in the Jasper area, if left unmanaged, may contribute to an increased adaptive potential for MPB in Alberta, further facilitating their expansion eastward.

The severity of infestation along the Jasper west park gate suggests the possibility of a new wave of invasion into Alberta (Jasper National Park 2016) that could, if left unchecked, continue to threaten valuable natural and managed forest resources. In the long term, the signature of admixture may assist future work on management and population genetics in two ways. First, distinct genetic signatures provide a means of tracking beetles as they spread further east and help to identify which areas are contributing to that spread (i.e., south, north, central). This approach could be used in tandem with traditional assessment methods (i.e., aerial surveys and pheromone traps). Second, the methods we describe could potentially be extended to manage spread risk of MPB longterm. For example, populations of pest species could be managed with the aim of reducing genetic diversity, an inverse of conservation management practices that try to promote genetic diversity in populations to ensure sufficient genetic variation for selection to act on. In conclusion, we describe a means of identifying mixed populations and tracking their spread across the landscape - outcomes that could complement existing management by predicting and reducing spread risk of MPB in the long term.

\section{Acknowledgements}

We would like to thank the anonymous reviewers for their helpful comments on the manuscript, as well as Bryan Brunet, Julian Dupuis and Kevin Muirhead for support in bioinformatics and data analysis; Giovanny Fagua for training in sample preparation; Taylor Becker for lab assistance; and Laval University's IBIS and University of Alberta's MBSU services for genotyping. We are grateful for beetle samples provided by Katherine Bleiker, Celia Boone, Jordan Burke, Barry Cooke, Mike Cunningham, Tom Hutchison, Devin Letourneau, Gillian MacDonald, Clint McCrea, Fraser McKee, Rory McIntosh, Chris MacQuarrie, Brent Murray, Colin Myrholm, Amanda Roe, Adrianne Rice, Erica Samis, Greg Smith, Brogan Waldner, Jeff Weber, Caroline Whitehouse, and Kristen Zentner. This research was supported by a grant from the Natural Science and Engineering Research Council of Canada (grant no. NET GP 434810-12) to the TRIA Network, with contributions from Alberta Agriculture and Forestry, fRI Research, Manitoba Conservation and Water Stewardship, Natural Resources Canada - Canadian Forest Service, Northwest Territories Environment and Natural Resources, Ontario Ministry of Natural Resources and Forestry, Saskatchewan Ministry of Environment, West Fraser and Weyerhaeuser.

\section{References}

Andrews, S. 2010. FastQC: A quality control tool for high throughput sequence data. http://www.bioinformatics.babraham.ac.uk/projects/fastqc (Accessed 13 Oct, 2016).

Batista, P.D., J.K. Janes, C.K. Boone, B.W. Murray and F.A.H. Sperling. 2016. Adaptive and neutral markers both show continentwide population structure of mountain pine beetle (Dendroctonus ponderosae). Ecol. Evol. 6: 6292-6300.
Bentz, B.J., J. Régnière, C.J. Fettig, E.M. Hansen, J.L. Hayes, J.A. Hicke, R.G. Kelsey, J.F. Negrón and S.J. Seybold. 2010. Climate change and bark beetles of the western United States and Canada: Direct and indirect effects. BioSci. 60: 602-613.

Bleiker, K.P., A.L. Carroll and G.D. Smith. 2011. Mountain pine beetle range expansion: Assessing the threat to Canada's boreal forest by evaluating the endemic niche. Mountain pine beetle working paper 2010-02. Natural Resources Canada, Canadian Forest Service, B.C., Canada.

Bleiker, K.P., R.J. Heron, E.C. Braithwaite and G.D. Smith. 2013. Pre-emergence mating in the mass-attacking bark beetle, Dendroctonus ponderosae (Coleoptera: Curculionidae). Can. Entomol. 145: 12-19.

Campbell, E.O., C.S. Davis, J.R. Dupuis, K. Muirhead and F.A.H. Sperling. 2017. Cross-platform compatibility of de novo- aligned SNPs in a non-model butterfly genus. Molecular Ecology Resources, online in advance of print.

Carroll, A.L., S.W. Taylor, J. Regniere and L. Safranyik. 2003. Effects of climate change on range expansion by the mountain pine beetle in British Columbia. In: Mountain Pine Beetle Symposium: Challenges and Solutions (Shore TL, Brooks JE, Stone JE eds.). Canadian Forest Service, Pacific Forestry Centre, Victoria, BC. Report BC-X-399. 223-232 p.

Catchen, J., R. Hohenlohe, S. Bassham, A. Amores and W. Cresko. 2013. Stacks: An analysis tool set for population genomics. Mole. Ecol. 22: 3124-3140.

Cooke, B. A. and A. L. Carroll. 2017. Predicting the risk of mountain pine beetle spread to eastern pine forests: Considering uncertainty in uncertain times. Forest Ecol. Manag. 396: 11-25.

Cullingham, C.I., J.E. Cooke, S. Dang, C.S. Davis, B.J. Cooke and D.W. Coltman. 2011. Mountain pine beetle host-range expansion threatens the boreal forest. Mole. Ecol. 20: 2157-2171.

Danecek P., A. Auton, G. Abecasis, C.A. Albers, E. Banks, M.A. DePristo, R.E. Handsaker, G. DiGuistini, S.Y. Wang, N.Y. Liao, G. Taylor, P. Tanguay, N. Feau, ... C.K. Tsui 2011. Genome and transcriptome analyses of the mountain pine beetle-fungal symbiont Grosmannia clavigera, a lodgepole pine pathogen. Proceedings of the National Academy of Sciences, USA 108. 2504-2509.

Dray, S., A.B. Dufour and D. Chessel. 2007. The ade4 package-II: Two-table and K-table methods. R News 7: 47-52.

Elshire, R.J., J.C. Glaubitz, Q. Sun, J.A. Poland, K. Kawamoto, E.S. Buckler and S.E. Mitchell. 2011. A robust, simple genotyping-bysequencing (GBS) approach for high diversity species. PLoS One 6: e19379.

Erbilgin, N., C. Ma, C. Whitehouse, B. Shan, A. Najar and M. Evenden. 2014. Chemical similarity between historical and novel host plants promotes range and host expansion of the mountain pine beetle in a naïve host ecosystem. New Phytol. 201: 940-950.

de la Giroday, HM. C., A.L. Carroll, B. S. Lindgren and B.H. Aukema. 2011. Incoming! Association of landscape features with dispersing mountain pine beetle populations during a range expansion event in western Canada. Landscape Ecol. 26: 1097.

Hicke, J.A., J.A. Logan, J. Powell and D.S. Ojima. 2006. Changing temperatures influence suitability for modeled mountain pine beetle (Dendroctonus ponderosae) outbreaks in the western United States. J. Geophys. Res.: Biogeosciences 111.

Hopkins-Hill, J. 2017. Mountain pine beetle numbers much higher than expected this year. Hinton Parklander, April 18, 2017. http://www.hintonparklander.com/2017/04/18/mountain-pine-beetlenumbers-much-higher-than-expected-this-year (accessed 4 June 2017). James, P.M., J.K. Janes, A.D. Roe and B.J. Cooke. 2016. Modeling Landscape-Level Spatial Variation in Sex Ratio Skew in the Mountain Pine Beetle (Coleoptera: Curculionidae). Environ. Entomol. 45: 790-801.

Janes, J.K. and P.D. Batista. 2016. The role of population genetic structure in understanding and managing pine beetles. In: Claus Tittiger, Gary J Blomquist, eds. Pine Bark Beetles, vol. 50, Advances in Insect Physiology. UK: Academic Press. 75-100 p. 
Janes J.K. and J. Hamilton. 2017. Mixing It Up: The Role of Hybridization in Forest Management and Conservation under Climate Change. Forests 8: 237-16.

Janes, J.K., A.D. Roe, A.V. Rice, J.C. Gorrell, D.W. Coltman, D.W. Langor and F.A.H. Sperling. 2016. Polygamy and an absence of fine-scale structure in Dendroctonus ponderosae (Hopk.) (Coleoptera: Curcilionidae) confirmed using molecular markers. Heredity 116: 68-74.

Janes, J.K., Y. Li, C.I. Keeling, M.M. Yuen, C.K. Boone, J. Cooke, J. Bohlmann, D.P.W. Huber, B. W. Murray, D.W. Coltman and F.A.H. Sperling. 2014. How the mountain pine beetle (Dendroctonus ponderosae) breached the Canadian Rocky Mountains. Mole. Biol. Evol. 31: 1803-1815.

Jasper National Park. 2016. Mountain Pine Beetle Management Plan. Parks Canada https://www.pc.gc.ca/en/nature/eco/feuvegfireveg/veg-veg/dpp-mpb. (accessed 21 June, 2017).

Keeling, C.I. et al. 2013. Draft genome of the mountain pine beetle, Dendroctonus ponderosae Hopkins, a major forest pest. Genome Biol. 14.

Lachowsky, L.E. and M.L. Reid. 2014. Developmental mortality increases sex-ratio bias of a size-dimorphic bark beetle. Ecol. Entomol. 39: 300-308.

Li, H. and R. Durbin. 2009. Fast and accurate short read alignment with Burrows-Wheeler transform. Bioinformatics 25: 1754-1760.

Mallet, J. 2007. Hybrid speciation. Nature 446: 279-283.

Martin, M. 2011. Cutadapt removes adapter sequences from highthroughput sequencing reads. EMBnet.journal 17: 10-12.

Pellow, K., G. Thandi and L. Unger. 2011. Mountain pine beetle survey in the Peace Region of British Columbia and adjacent areas in Alberta. Mountain pine beetle working paper 2010-05. Natural Resources Canada, Canadian Forest Service, B.C., Canada.

Poland, J.A., P.J. Brown, M.E. Sorrells and J.L. Jannink. 2012. Development of high-density genetic maps for barley and wheat using a novel two-enzyme genotyping-by-sequencing approach. PLoS ONE 7: e32253.

Raffa, K. F., B.H. Aukema, B.J. Bentz, A.L. Carroll, J.A. Hicke, M.G. Turner and W. H. Romme. 2008. Cross-scale drivers of natural disturbances prone to anthropogenic amplification: The dynamics of bark beetle eruptions. Biosci. 58: 501-517.

R Development Core Team. 2008. R: A language and environment for statistical computing. R Foundation for Statistical Computing, Vienna, Austria. ISBN 3-900051-07-0. http://www.R-project.org.
Rieseberg, L.H., and J.M. Burke. 2001. The biological reality of species: gene flow, selection, and collective evolution. Taxon 50: $47-67$.

Robertson, C., T.A Nelson, D.E. Jelinski, M.A. Wulder and B. Boots. 2009. Spatial-temporal analysis of species range expansion: The case of the mountain pine beetle, Dendroctonus ponderosae. J. Biogeog. 36: 1446-1458.

Roe, A.D., A.V. Rice, S.E. Bromilow, J.E. Cooke and F.A.H. Sperling. 2010. Multilocus species identification and fungal DNA barcoding: insights from blue stain fungal symbionts of the mountain pine beetle. Mole. Ecol. Res. 10: 946-959.

Rosenberger, D. W., R. C. Venette, M. P. Maddox and B. H. Aukema. 2017a. Colonization behaviors of mountain pine beetle on novel hosts: Implications for range expansion into northeastern North America. PloS one 12: $\mathrm{e} 0176269$.

Rosenberger, D. W., B. H. Aukema and R. C. Venette. 2017b. Cold tolerance of mountain pine beetle among novel eastern pines: A potential for trade-offs in an invaded range? Forest Ecol. Manage. 400: 28-37.

Safranyik, L., A.L. Carroll, J. Regniere, D.W. Langor, W.G. Riel, T.L. Shore, B. Peter, B.J. Cooke, V.G. Nealis and S.W. Taylor. 2010. Potential for range expansion of mountain pine beetle into the boreal forest of North America. Can. Entomol. 142: 415-442.

Samarasekera, G.D.N., N.V. Bartell, B.S. Lindgren, J.E. Cooke, C.S. Davis, P. James, ... B.W. Murray. 2012. Spatial genetic structure of the mountain pine beetle (Dendroctonus ponderosae) outbreak in western Canada: Historical patterns and contemporary dispersal. Mole. Ecol. 21: 2931-2948.

Swofford, D.L. 2002. PAUP*. Phylogenetic Analysis Using Parsimony (*and other methods). Version 4. Sinaur Associates, Sunderland, Massachusetts. https://people.sc.fsu.edu/ dswofford/paup_test/. Tsui, C.K., B. Wang, L. Khadempour, S.M. Alamouti, J. Bohlmann, B.W. Murray and R.C. Hamelin. 2010. Rapid identification and detection of pine pathogenic fungi associated with mountain pine beetles by padlock probes. J. Microbiol. Meth. 83: 26-33.

Wickham, H. 2009. ggplot2: Elegant Graphics for Data Analysis. Springer-Verlag New York. ISBN 978-0-387-98140-6. http://ggplot2.org. 